\title{
INTENSIFICATION OF THE EXTRACTION PROCESS OF PHENOLIC COMPOUNDS FROM ACORUS CALAMUS LEAVES
}

\author{
Oleksiy Andryushayev, Olena Ruban, Yuliia Maslii, Inna Rusak
}

The aim. To determine the intensified method of extraction of phenolic compounds from Acorus calamus leaves and optimal conditions for the process.

Materials and methods. In order to develop the optimal intensified method of extraction samples were prepared in different conditions of raw materials-extractant ratio, temperature, time and multiplicity. As a raw materials spectrophotometrically pre-standardized Acorus calamus leaves were used. The extraction was carried out in a hermetically sealed ultrasonic extraction reactor PEX 1 (REUS, Contes, France). As the criteria of extraction efficiency were indicators of dry residue and total amount of flavonoids determined using methods described in State Pharmacopoeia of Ukraine. The amount of flavonoids was determined spectrophotometrically on a certified device Specord 200 (Analytik Jena, Germany).

Results. According to our research results it was found that ultrasonic action and addition of surfactant significantly improves the efficiency of the extraction process. The optimal conditions for the process were determined. Experimentally proved that the rational raw material-extractant ratio is 1:15. Comparative study of the extraction process with different temperatures showed that the highest amount of extractives is achieved at temperature $70{ }^{\circ} \mathrm{C}$ and 45 min of duration. The optimal extraction multiplicity is 3.

Conclusions. As a result of the study, the intensified extraction method for Acorus calamus leaves - re-maceration with ultrasound - was established. The conducted researches allowed to develop the method of extraction, expedient in the conditions of the modern pharmaceutical industry

Keywords: Acorus calamus leaves, phenolic compounds, extraction process, re-maceration, ultrasonic action, surfactant-mediated extraction

How to cite:

Andryushayev, O., Ruban, O., Maslii, Y., Rusak, I. (2021). Intensification of the extraction process of phenolic compounds from Acorus calamus leaves. ScienceRise: Pharmaceutical Science, 4 (32), 4-10. doi: http://doi.org/10.15587/2519-4852.2021.238329

(C) The Author(s) 2021

This is an open access article under the Creative Commons CC BY license hydrate

\section{Introduction}

Phytotherapeutic treatment of most diseases has been known to mankind since ancient times. In folk medicine, there are many recipes that our ancestors used to treat, prevent or alleviate the symptoms of various pathologies.

Modern therapy is mainly based on synthetic drugs. Fast and strong action makes them attractive to consumers, however, in the case of long-term use, they are dangerous to public health. That is why many modern studies are aimed to develop new drugs based on medicinal plant raw materials. The main argument in favor of the use of phytopreparations is their safety and complex effect on the human body, which provides high efficiency with minimal risk of side effects $[1,2]$.

The factor of drugs affordability is also important for the population of Ukraine. Socio-political changes in recent years have led to a decline in living standards and manufactured medicines, especially imported ones, unaffordable for the majority of the population. Herbal based preparations are much cheaper than synthetic, which provide low cost of the final product.
Sweet flag (latin Acorus calamus L.) is a worldfamous medicinal plant (MP) with valuable therapeutic properties. It is estimated that the word "calamus" "cane", "reed" - is older than Latin and ancient Greek languages and existed in the Proto-Indo-European language, which indicates the centuries-old experience of using this MP. Its healing properties have been known to mankind since ancient Egypt, Greece and Rome. The ancient Greek physician Dioscorides in his work "De materia medica" ("Medicinal substances") advised to use calamus in cases of liver and gastrointestinal tract diseases, as well as a tonic.

In Ayurvedic medicine, sweet flag is widely used to strengthen the body. It was also popular among Native Americans and was considered a plant with significant healing effects. Later, their experience was adopted by immigrants from Europe.

Today in the modern scientific literature numerous researches on pharmacological activity of calamus and extracts from it are described. A number of authors worked on the topic - Kaushik, S., Gohain, K., Derimedvid L. V., Korang L. A., Kalko K. O., Verei- 
tinova V. P., Shakina T. M., Khan, B., Bakht, J., etc. Significant anti-exudative activity was revealed, which is explained by such mechanisms as: the ability of the extract of the studied raw material to have an inhibitory effect on the mediators of the early phase of the inflammatory process (biogenic amines, prostaglandins); stabilization of cell and subcellular membranes; indirect or direct inhibition of cyclooxygenase [3]. Activity towards the hepatobiliary system is also described. The extract intake leads to a significant reduction in the intensity of the cholestasis process, improvement of bile-secretory and bile-forming function of the liver [4]. Acorus calamus leaves inherent antioxidant and anticytolytic properties, which are confirmed through a significant decrease in the activity of AST, ALT and gHTTP. Hepatoprotective activity was observed. Studies on actoprotective activity in mice indicated an increase in physical endurance by $15-17 \%$ [5]. The prophylactic antiulcer effect of calamus leaves extract is proven [6]. Dose-dependent thymoleptic activity of dealcoholized Acorus leaves extract, associated with the effect of inert neurotransmission on catechols, was shown. The thymoleptic effects of the extract may be due to the presence of hyperoside, rosmarinic acid and a number of other flavonoids [7].

Flavonoids are the main class of active compounds that determine the healing properties of calamus leaves extract. Although the exact mechanism of their action is unknown, it is believed that they prevent the influx of calcium into cells by inhibiting the enzyme phosphodiesterase cAMP. B cells create a high concentration of cAMP that prevents degranulation and release of pro-inflammatory mediators. Inhibitory activity against $\mathrm{IL}-4$, which is closely related to the development of inflammation, has also been observed. Some flavonoids inhibit the activity of tumor necrosis factor (TNF- $\alpha$ ) and the production of nitrogen oxide (NO) by macrophages. Flavonoids such as luteolin and quercetin enhance the anti-inflammatory activity of the cytokine IL-10. The hydroxyl groups at positions 5, 7, 30 and 40, together with the double bonds at position $\mathrm{C} 2-\mathrm{C} 3$, have been shown to be associated with anti-inflammatory activity. The property of flavonoids to neutralize free radicals is also important, which has a positive effect on the dynamics of the inflammatory process $[8,9]$.

Asarones are also important active components of sweet flag, among which $\beta$-asarone is most active. Due to high lipophilicity, it easily pass through the bloodencephalic barrier and affect the central nervous system [10]. However, many studies confirm toxicity of $\beta$-asarone. Back in the last century, many studies have been published in which the carcinogenicity of $\beta$-asarone was established, forcing many traditional healers to avoid the therapeutic use of calamus. In 2005, the European Medicines Agency issued a public statement restricting the use of drugs containing asarone [11-14]. Discussions on this topic continue today.

In Ukraine, Acorus calamus is an official MP [15]. About 20 drugs have been registered on the domestic pharmaceutical market, which contain exclusively the rhizomes of Acorus calamus. Ignoring other parts of the plant leads to irrational use of natural resources and reduce the species prevalence. Moreover, a number of authors point to the similarity of the qualitative composition of biologically active substances (BAS) of rhizomes and leaves of sweet flag. According to the results of researches, the quantitative content of essential oils and flavonoids in alcoholic extracts from the rhizomes and leaves of calamus was almost equal, while the detected content of phenolic compounds in the leaves was much higher. The total amino acid content in the leaves was almost twice as high as in the rhizomes. The content of macro- and microelements slightly prevailed in the leaves. The results indicate the chemical equivalence of extracts from the rhizomes and leaves of Acorus calamus [16]. It is also important to note that asarone was not found in the leaves of calamus, which indicates a significant advantage of leaves over the rhizomes [17].

Literature sources review revealed some technological parameters of phenolic compounds extraction from Acorus calamus leaves: optimal degree of grinding 1-2 mm and extractant - ethyl alcohol $70 \%$ [18]. However, no modern intensified extraction method was found, which provides the relevance of research in this direction.

There are many methods to intensify the extraction of BAS from plant raw material which can be divided into 2 large groups: conventional and nonconventional.

In conventional extraction methods such as remaceration, percolation and reflux extraction, difference of concentrations in raw materials and extractant is used which is achieved by creating dynamic extraction conditions [19].

Operation principle of nonconventional extraction methods is based on the action of different physical factors (vibrations, pulsations, pressure, deformations, etc.) on the raw material in the extractant medium. The most commonly used methods are pressurized extraction, microwave assisted extraction, pulsed electric field extraction and ultrasound assisted extraction [20,21].

Among the various methods of extraction we chose a combination of conventional and nonconventional methods - re-maceration with use of ultrasonic action, which has a high potential, especially for flavonoids. Combination of ultrasonic effects (alternating sound pressure, sound wind, cavitation) together with the constant renewal of the extractant provide fluid penetration into cracks and capillaries of plant raw materials and, accordingly, provide the highest yield of BAS [22, 23].

The literature review has drawn our attention to a fundamentally different way of intensifying the extraction process - the addition of surface-active agents (surfactants). Some studies have found that the use of surfactants increased the yield and rate of extraction of essential oils, alkaloids and glycosides. The addition of small amounts of surfactants $(0.01-0.1 \%)$ improved the extraction process, and in some cases the completeness of the extraction was achieved with a smaller amount of extractant. These effects occur due to reducing the surface tension at the interface, improving the wettability of the cell contents and facilitating the penetration of the extractant. In addition, a significant role is played by solubilizing ability of surfactants [24]. All this contributes to the diffusion of BAS from the plant cell into the extractant. Given the above data, the use of surfactants in 
extraction process was taking into account for this research.

Thus the aim of our work was to determine the intensified method of extraction of phenolic compounds from Acorus calamus leaves and optimal conditions for the process.

\section{Planning (methodology) of research}

The development of the optimal method of extraction of BAS from raw materials of Acorus calamus leaves includes not only the search for a new method based on the chemical composition of the raw material, but also the determination of optimal process conditions. Taking into account that some parameters of exctraction from Acorus calamus leaves - optimal degree of grinding and extractant - were estimated in previous studies [18], it was necessary to determine the following conditions:

- rational ratio of raw materials and extractant;

- the feasibility of using physical methods, such as ultrasound, to intensify the process;

- temperature and extraction time;

- multiplicity of extractant change.

The study consists of theoretical and practical substantiation of the developed extraction conditions. Extract samples obtained under different conditions were compared by dry residue and content of flavonoids extracted from the raw material.

\section{Materials and methods}

Acorus calamus leaves were harvested in Poltava region (Ukraine) in the flowering stage (July-August), when largest accumulation of BAS in their composition is observed. Drying was conducted using air-shadow method at a temperature of $20-35^{\circ} \mathrm{C}$, avoiding exposure by direct sunlight. The dried raw materials were subjected to quality control in accordance with the project for quality control methods.

Extraction and research were carried out in the Educational Research Institute of Applied Pharmacy of National University of Pharmacy (Kharkiv, Ukraine).

The selected extraction method - re-maceration with $70 \%$ ethanol using ultrasound. The process of extraction was conducted without pre-soaking of raw materials in a hermetically sealed ultrasonic extraction reactor PEX 1 (REUS, Contes, France), capacity of the reactor $3 \mathrm{~L}$.; ultrasound frequency $-35 \mathrm{kHz}$, degree of grinding of raw materials $-1-2 \mathrm{~mm}$. The obtained extracts were stored at temperature $+10{ }^{\circ} \mathrm{C}$ for 2 days and filtered through an ashless paper filter under vacuum.

Determination of the obtained extracts dry residue was performed according to the procedure described in State Pharmacopoeia of Ukraine (SPhU) 2 ed., item 8.2.16 [15].

Quantitative flavonoid content of Acorus calamus leaves and different extraction samples was evaluated using double-beam spectrophotometer Specord 200 (Analytik Jena, Germany) with the method "Hawthorn leaves and flowers", SPhU monograph. The amount of flavonoids was calculated in terms of hyperoside [25].

Studies on the asarone content were performed by thin layer chromatography according to the $\mathrm{SPhU}$ (2.2.27) [25].
Statistical analysis was carried out using Microsoft Excel 2016 software. All experimental determinations were done in triplicate and results are presented as mean value \pm confidence interval (CI). Significant levels were defined at $\mathrm{p}<0.05$.

\section{Results}

In the first stage of our research we studied the quantitative content of flavonoids in Acorus calamus leaves, which was $1.089 \pm 0.004 \%$ in terms of hyperoside. The results of the study proved that the raw material meets the requirements of the quality control methods project (at least $1 \%$ ). The absorption spectrum is shown in Fig. 1.

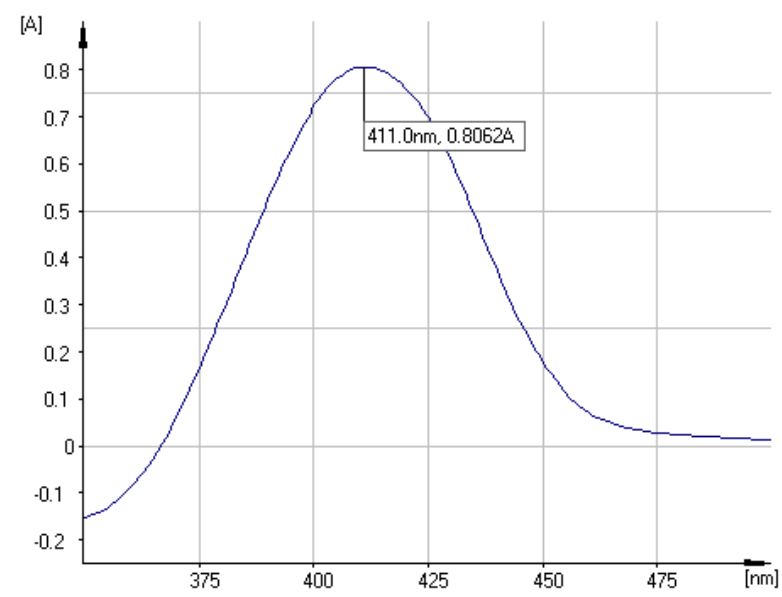

Fig. 1. Adsorption spectrum of Acorus calamus leaves

Then it was necessary to determine the asarone content of Acorus calamus leaves. On the chromatogram, the test zone of asarone was not more intense than the corresponding zone of the reference solution. According to the results, the raw material meets the requirements of the quality control methods project (not more than $0.5 \%$ ).

The next step was to determine the optimal ratio raw-extractant. For this purpose, extracts with the ratio of raw materials to extractant 1:5, 1:10, 1:15 and 1:20 were obtained. Evaluation of the efficiency of extraction of BAS was performed on the basis of dry residue in terms of 1.0 of raw material. The extraction was performed using ultrasound at a temperature of $30{ }^{\circ} \mathrm{C}$ for 60 minutes. The results of the study are shown in Fig. 2.

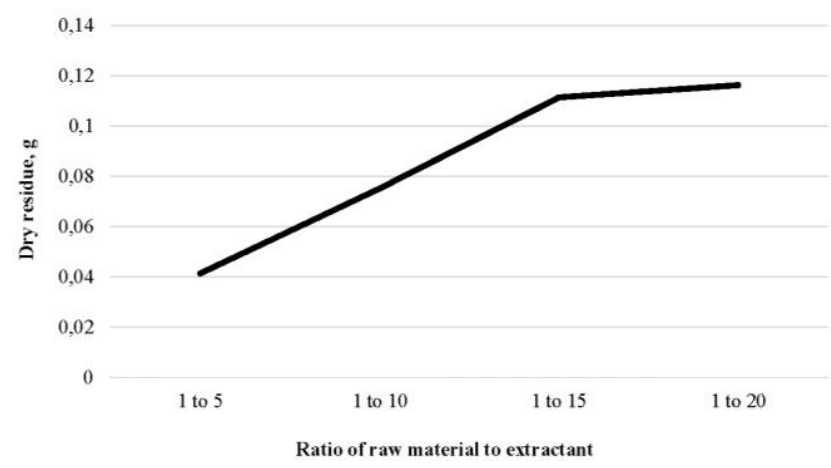

Fig. 2. Determination of optimal raw material to extractant ration 
The data indicate that the optimal ratio of raw calamus leaves to extractant was 1:15. This ratio was used in the following studies.

Further work has been devoted to studying the impact of various temperature conditions and time of the process on the extraction in terms of dry residue (Fig. 3) and flavonoid content (Fig. 4). Sampling was performed every 15 minutes.

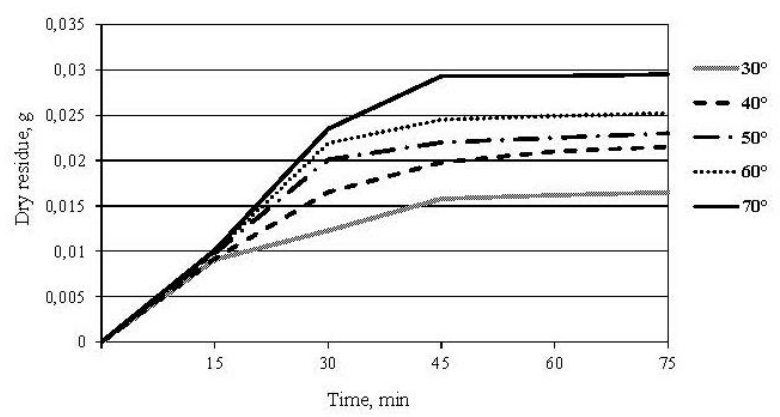

Fig. 3. Determination of the optimal temperature and time of extraction based on the dry residue

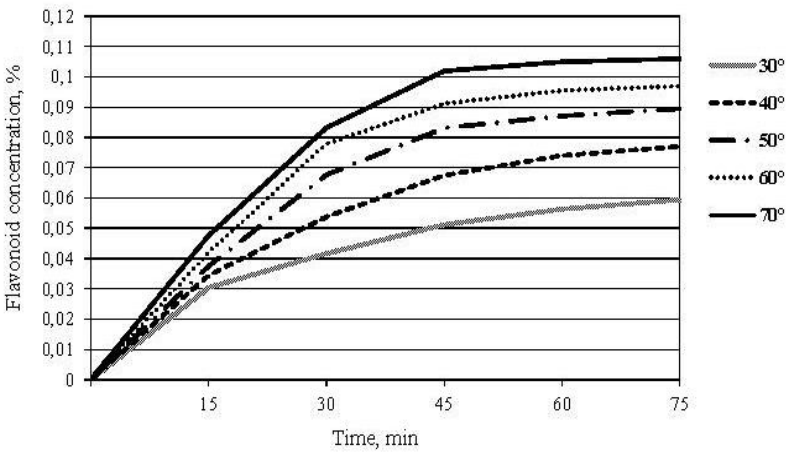

Fig. 4. Determination of the optimal temperature and time of extraction based on the amount of flavonoids

According to the obtained results (Fig. 3, 4) the most complete depletion of raw materials was achieved in 45 minutes of extraction at $70{ }^{\circ} \mathrm{C}$.

In the next stage a comparative study in abovedefined conditions without the use of ultrasound was carried out. The results are shown in Fig. 5 and 6.

At the next stage of the study, the optimal multiplicity of extractant changes was determined. The results are shown in Fig. 7 and 8.

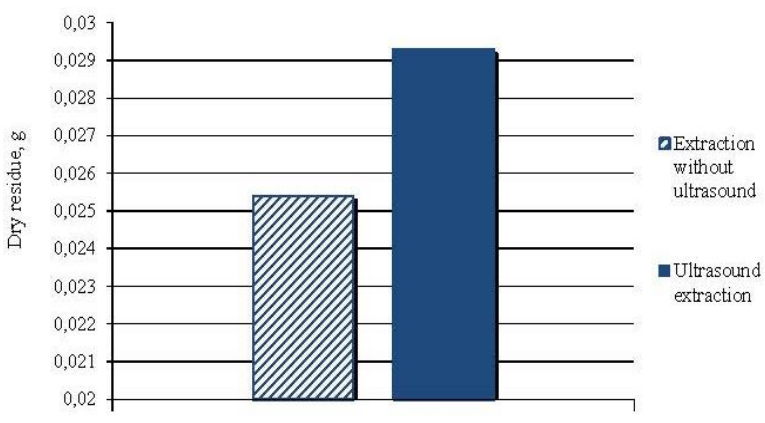

Fig. 5. Ultrasound effect on the amount of dry residue

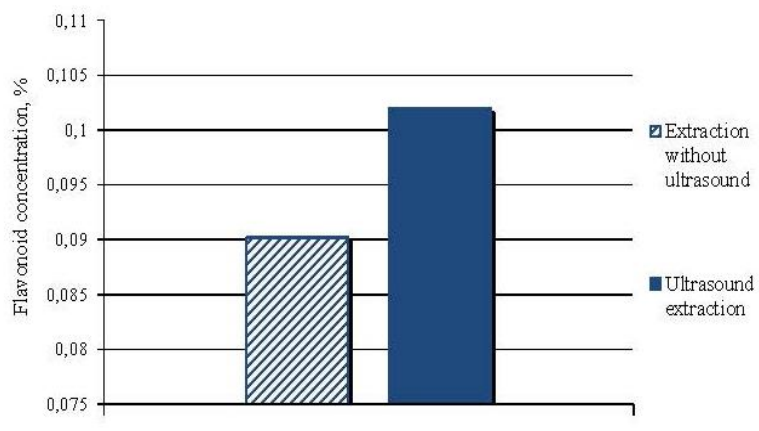

Fig. 6. Ultrasound effect on the amount of flavonoids

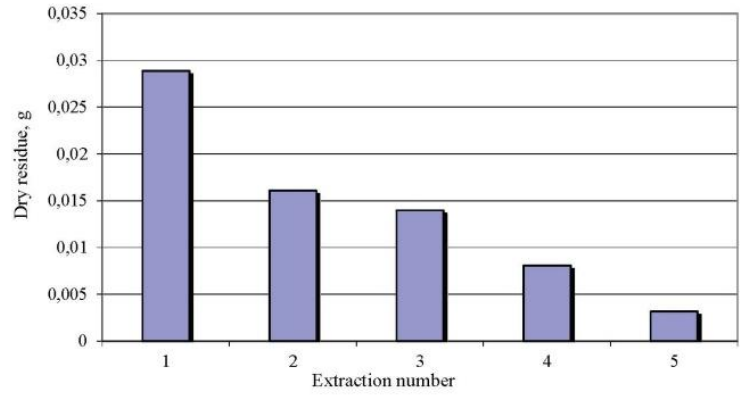

Fig. 7. Determination of the optimal extraction multiplicity based on the dry residue

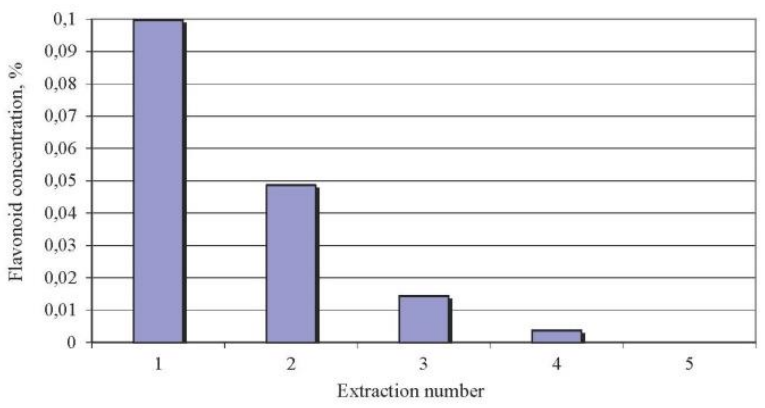

Fig. 8. Determination of the optimal extraction multiplicity based on the amount of flavonoids

According to the obtained results, the most optimal is a 3-fold change of the extractant.

To determine the rational amount of surfactants, extraction was performed in above-defined conditions with different concentrations of polysorbate-80 in the extractant. The results of the study are shown in Fig. 9 and 10 .

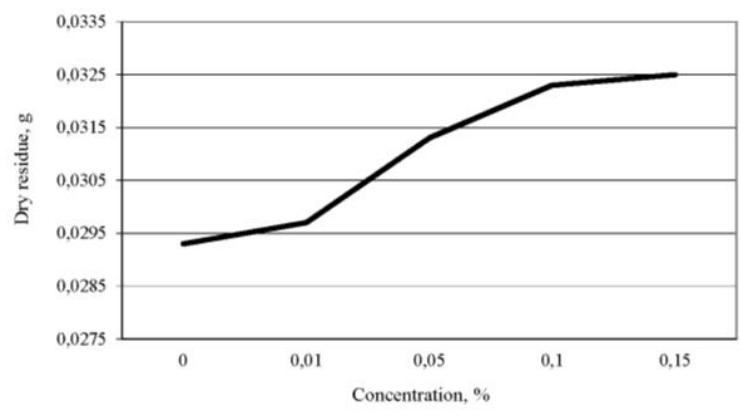

Fig. 9. Effect of polysorbate- 80 on the amount of dry residue 


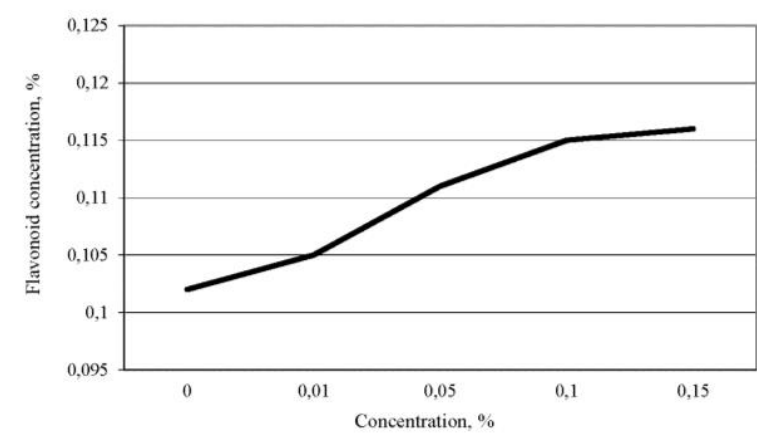

Fig. 10. Effect of polysorbate-80 on the amount of flavonoids

Results of the study (Fig. 9, 10) indicate that the surfactant addition improved yield of BAS from calamus leaves. The estimated rational concentration of polysorbate- 80 was $0.1 \%$ compared to the volume of extractant as further increase of its amount did not contribute to the extraction efficiency.

\section{Discussion}

According to Fig 2, the optimal ratio of raw material and extractant was experimentally established $-1: 15$. Reducing the liquid phase to 1:10 leads to a significant decrease in dry residue for $67.48 \%$, while the ratio of 1:20 was associated with a little increase in dry residue for $4.14 \%$ but caused significant increment of extractant volume, which reduced the concentration of BAS in the extract and made this ratio economically impractical.

The determination of the optimum extraction temperature (Fig. 3, 4) indicated, that the increase in temperature greatly affected the extraction process. Under the influence of this factor there was a better rupture of cellular structures of the plant, which together with the increase in kinetic rate energy of molecules and a decrease in the viscosity of the extractant accelerated the diffusion process [24]. Further increase in temperature did not lead to a significant increase in the amount of extractives.

According to the literature sources, it is known that ultrasonic waves create alternating pressure, which promotes increased mass transfer and causes cavitation; rupture of cavitation bubbles generates macroturbulence and high rate of interparticle collision, replacing molecular diffusion with more efficient convective mass transfer [26]. Powerful ultrasonic waves significantly increase the rate of impregnation with extractant of various materials having a capillary structure. Ultrasound, creating a sound-capillary effect, accelerates the displacement of air bubbles and creates conditions for their dissolution in the extractant. A vacuum is formed, which causes so-called sponge effect and, as a result, the soaking time of raw materials under the action of ultrasound significantly reduces $[19,27]$. Therefore, at the next stage it was necessary to determine the feasibility of using ultrasound in Acorus calamus leaves extraction. According to the obtained results, the yield of BAS from calamus leaves when using ultrasound was higher by almost $15 \%$ compared to extraction without ultrasound (Fig. 5, 6).

It is a well-known fact that one of the most important driving forces of the diffusion process is the dif- ference in the concentration of BAS in the raw material and extractant. Therefore, in order to increase the efficiency of the extraction process, periodic change of the extractant was included in the technological process.

Analysis of the results on the dry residue (Fig. 7) showed that the $2^{\text {nd }}, 3^{\text {rd }}, 4^{\text {th }}$ and $5^{\text {th }}$ portions of extractant had respectively $55.71 \%, 48.44 \%, 28.03 \%$ and $11.07 \%$ of the $1^{\text {st }}$ portion's dry residue. Spectrophotometric study showed the following results: $2^{\text {nd }}$ and $3^{\text {rd }}$ portions had respectively $48.8 \%$ and $16.43 \%$ of the $1^{\text {st }}$ portion while in the 4th portion there was only $3.81 \%$. Analysis of the 5 th portion did not reveal the content of polyphenolic compounds at all (Fig. 8). That is, the transition of flavonoids from raw materials to the extractant was almost completed on the 3rd portion of the extractant.

Obviously, the difference in the results of the total amount of extractives and the amount of flavonoids in the extracts can be explained by the fact that a significant amount of dry residue was maintained due to the contribution of other BAS of calamus leaves. Therefore, it's optimal to use 3 portions when obtaining an extract from Acorus calamus leaves.

In choosing the appropriate surfactant, we were primarily guided by the nature of the target extractive compounds and extractant. To extract polyphenols, it was necessary to use a substance with good solubility in water and ethyl alcohol and high hydrophilic-lipophilic balance (HLB), which would promote the solubilization of hydrophilic components. All these requirements are met by polysorbate-80, which is a hydrophilic surfactant with HLB 14.5-15. In addition, it is a chemically neutral compound with good safety profile, the use of which is allowed even in injectable solutions [28, 29].

The results of the study confirmed the data of literature sources and allowed to determine the optimal concentration of polysorbate-80 (Fig. 9, 10).

Study limitations. Studies conducted to establish the optimal conditions for the extraction of BAS from calamus leaves do not reflect all possible risks associated with the implementation of the technology in the factory and require additional research on the industrial equipment available for the manufacturer.

Prospects for further research. A promising direction for further research is development of the final composition of a new original drug based on Acorus calamus leaves, pharmacological research, development of technological regulatory documentation for its production, verification of the coherence of the developed drug with quality parameters, as well as justification of the technological process.

\section{Conclusions}

As a result of a number of studies based on indicators of dry residue and flavonoid content, the optimal method of extraction of BAS from acorus calamus leaves was determined - ultrasound assisted re-maceration, which allowed to intensify the process of obtaining the extract.

Optimal technological parameters for the extraction process were experimentally established:

- ratio of raw materials to extractant $-1: 15$;

- temperature $-70{ }^{\circ} \mathrm{C}$;

- time of extraction -45 minutes; 
- multiplicity of extractions -3 -fold collection of the extract.

It is proved that the preliminary introduction of surfactants into the extractant, namely polysorbate-80, promotes a more complete extraction of flavonoids and other BAS from calamus leaves. The optimal concentration of polysorbate- 80 in the extractant was $0.1 \%$.

The obtained results are part of the $\mathrm{PhD}$ thesis "Development of the composition and technology of tablets based on Acorus calamus leaves" and are going to be used in further research.

\section{Conflict of interests} interests.

The authors declare that they have no conflict of

\section{Financing}

The study was performed without financial support.

1. Compendium on-line. Available at: https://compendium $\begin{array}{r}\text { References } \\ \text {. }\end{array}$

2. Salmerón-Manzano, E., Garrido-Cardenas, J. A., Manzano-Agugliaro, F. (2020). Worldwide Research Trends on Medicinal Plants. International Journal of Environmental Research and Public Health, 17 (10), 3376. doi: http://doi.org/10.3390/ijerph17103376

3. Yadav, D., Srivastava, S., Tripathi, Y. B. (2019). Acorus Calamus A Review. International Journal of Scientific Research in Biological Sciences, 6 (4), 62-67. doi: http://doi.org/10.26438/ijsrbs/v6i4.6267

4. Derimedvid, L. V., Korang, L. A., Kalko, K. O., Vereitinova, V. P. (2020). Effect of Acorus calamus leaf extract on cholestasis and biliary excretion at the experimental hepatitis. Pharmacology and Drug Toxicology, 14 (2), 114-121. doi: http://doi.org/10.33250/ 14.02.114

5. Khan, B. M., Bakht, J. (2018). Effect of sun-drying on anti-fungal, anti-yeast and antioxidant potency of Acorus calamus, an indigenous medicinal plant. Pakistan Journal of Botany, 51 (1). doi: http://doi.org/10.30848/pjb2019-1(42)

6. Babar, P. S., Deshmukh, A. V., Salunkhe, S. S., Chavan, J. J. (2020). Micropropagation, polyphenol content and biological properties of Sweet Flag (Acorus calamus): a potent medicinal and aromatic herb. Vegetos, 33 (2), 296-303. doi: http://doi.org/10.1007/ s42535-020-00107-8

7. Derimedved, L. V., Korang, L. A., Yudkevich, T. K. (2020). Timoleptic properties of dealcoholized extract of calamus leaves (Acorus calamus L.). Norwegian Journal of Development of the International Science, 40, 44-49.

8. Kaushik, S., Gohain, K. (2019). Study of the anticonvulsant activity of ethanolic extract of root of acorus calamus in albino rats. Asian Journal of Pharmaceutical and Clinical Research, 12 (1), 185. doi: http://doi.org/10.22159/ajpcr.2019.v12i1.29004

9. Cruz, E. A., Muzitano, M. F., Costa, S. S., Rossi-Bergmann B. (2012). Preventive Phytotherapy of Anaphylaxis and Allergic Reactions. Allergic Diseases - Highlights in the Clinic, Mechanisms and Treatment, 461-476. doi: http://doi.org/10.5772/25835

10. Sharma, V., Sharma, R., Gautam, D., Kuca, K., Nepovimova, E., Martins, N. (2020). Role of Vacha (Acorus calamus Linn.) in Neurological and Metabolic Disorders: Evidence from Ethnopharmacology, Phytochemistry, Pharmacology and Clinical Study. Journal of Clinical Medicine, 9 (4), 1176. doi: http://doi.org/10.3390/jcm9041176

11. Abel, G. (1987). Chromosomenschädigende Wirkung von $\beta$-Asaron in menschlichen Lymphocyten. Planta Medica, 53 (3), 251-253. doi: http://doi.org/10.1055/s-2006-962694

12. Hasheminejad, G., Caldwell, J. (1994). Genotoxicity of the alkenylbenzenes $\alpha-$ and $\beta$-asarone, myristicin and elemicin as determined by the UDS assay in cultured rat hepatocytes. Food and Chemical Toxicology, 32 (3), 223-231. doi: http://doi.org/10.1016/02786915(94)90194-5

13. Public Statement on the use of herbal medicinal products containing asarone. European Medicines Agency Evaluation of Medicines for Human Use (2005). Doc Ref: EMEA / HMPC / 139215/2005. London.

14. Patil, P. J., Patil, V. R. (2016). Phytochemical and Toxicological Evaluation of Acorus calamus and Argyreia speciosa Leaves Extract. Research Journal of Pharmacognosy and Phytochemistry, 8 (3), 121-124. doi: http://doi.org/10.5958/0975-4385.2016.00022.4

15. Derzhavna Farmakopeia Ukrainy. Vol. 1 (2018). Kharkiv: Derzhavne pidpryiemstvo «Ukrainskyi naukovyi farmakopeinyi tsentr yakosti likarskykh zasobiv», 1128.

16. Sofyan, A., Widodo, E., Natsir, H. (2017). Bioactive Component, Antioxidant Activity, and Fatty Acid Profile of Red Beewort (Acorus sp) and White Beewort (Acorus calamus). Jurnal Teknologi Pertanian, 18 (3), 173-180. doi: http://doi.org/10.21776/ ub.jtp.2017.018.03.17

17. Derymedvid, L., Korang, L., Shakina, L. (2020). Comparative cytotoxic analysis of extracts obtained from leaves and roots of sweet flag (Acorus Calamus L.) on rat bone marrow cells in vitro. ScienceRise: Pharmaceutical Science, 1 (23), 17-22. doi: http://doi.org/10.15587/2519-4852.2020.196405

18. Yaremenko, M., Gontova, T., Boryak, L., Mala, O., Andryushayev, O. (2020). Determination of optimal extraction conditions of phenolic compounds from acorus calamus leaves. EUREKA: Health Sciences, 3, 63-70. doi: http://doi.org/10.21303/25045679.2020 .001317

19. Đukić, D., Mašković, P., Vesković Moračanin, S., Kurćubić, V., Milijašević, M., Babić, J. (2017). Conventional and unconventional extraction methods applied to the plant, Thymus serpyllum L. IOP Conference Series: Earth and Environmental Science, 85, 012064. doi: http://doi.org/10.1088/1755-1315/85/1/012064

20. Zhang, Q.-W., Lin, L.-G., Ye, W.-C. (2018). Techniques for extraction and isolation of natural products: a comprehensive review. Chinese Medicine, 13 (1). doi: http://doi.org/10.1186/s13020-018-0177-x

21. Rahman, H., Arini, S. F., Utomo, V. (2020). Tannins Extraction of Tea Leaves by Ultrasonic Method: Comparison with The Conventional Method. Jurnal Teknologi, 8 (1), 84-95. doi: http://doi.org/10.31479/jtek.v1i8.62

22. Dal, O., Şengün, D., Yüksel Özşen, A. (2020). Ultrasound Assisted Extraction for the Recovery of Phenolic Compounds from Waste Hazelnut Shell. Environmental Research and Technology. doi: http://doi.org/10.35208/ert.763459

23. Nitiwattananon, A., Thanachasai, S. (2019). Comparison of Conventional and Ultrasound-Assisted Extraction Techniques for Extraction of Phenolic Compounds from Coconut Husk. Applied Mechanics and Materials, 891, 83-89. doi: http://doi.org/10.4028/www.scientific.net/amm.891.83 
24. Mahmud, I., E. S. Mirghani, M., Yusof, F., Al-khatib, M. (2019). Effects of Time, Temperature, and Solvent Ratio on the Extraction of Non-Extractable Polyphenols with Anticancer Activity of Barhi Date Palm Kernels Extracts Using Response Surface Methodology. doi: http://doi.org/10.20944/preprints201907.0055.v1

25. Derzhavna Farmakopeia Ukrainy. Vol. 3 (2018). Kharkiv: Derzhavne pidpryiemstvo «Ukrainskyi naukovyi farmakopeinyi tsentr yakosti likarskykh zasobiv»», 732.

26. Baghdikian, B., Filly, A., Fabiano-Tixier, A.-S., Petitcolas, E., Mabrouki, F., Chemat, F., Ollivier, É. (2016). Extraction by solvent using microwave and ultrasound-assisted techniques followed by HPLC analysis of Harpagoside from Harpagophytum procumbens and comparison with conventional solvent extraction methods. Comptes Rendus Chimie, 19 (6), 692-698. doi: http://doi.org/10.1016/j.crci.2016.02.020

27. Liu, Y., She, X.-R., Huang, J.-B., Liu, M.-C., Zhan, M.-E. (2018). Ultrasonic-extraction of phenolic compounds from Phyllanthus urinaria: optimization model and antioxidant activity. Food Science and Technology, 38 (suppl 1), 286-293. doi: http://doi.org/10.1590/1678-457x.21617

28. Melro, E., Valente, A. J. M., Antunes, F. E., Romano, A., Medronho, B. (2021). Enhancing Lignin Dissolution and Extraction: The Effect of Surfactants. Polymers, 13 (5), 714. doi: http://doi.org/10.3390/polym13050714

29. Ruban, O. A., Pertsev, I. M., Kutsenko, S. A., Maslii, Yu. S. (2016). Excipients in the manufacture of drugs. Kharkiv: Golden Pages, 720.

Received date 03.06.2021

Accepted date 23.07.2021

Published date 31.08.2021

Oleksiy Andryushayev*, Postgraduate Student, Department of Industrial Technology of Drugs, National University of Pharmacy, Pushkinska str., 53, Kharkiv, Ukraine, 61002

Olena Ruban, Doctor of Pharmaceutical Sciences, Professor, Head of Department, Department of Industrial Technology of Drugs, National University of Pharmacy, Pushkinska str., 53, Kharkiv, Ukraine, 61002

Yuliia Maslii, PhD, Associate Professor, Department of Industrial Technology of Drugs, National University of Pharmacy, Pushkinska str., 53, Kharkiv, Ukraine, 61002

Inna Rusak, Leading Specialist, Educational and Scientific Training Laboratory of Chemical and Technological Research, National University of Pharmacy, Pushkinska str., 53, Kharkiv, Ukraine, 61002

*Corresponding author: Oleksiy Andryushayev, e-mail: linuks454@gmail.com 